\section{Original Article}

\section{Corresponding Author}

Kyung Hyun Kim

(iD https://orcid.org/0000-0002-1338-5523

Department of Neurosurgery, Spine and Spinal Cord Institute, Gangnam Severance Hospital, Yonsei University College of

Medicine, 211 Eonju-ro, Gangnam-gu,

Seoul 06273, Korea

Email: nskhk@yuhs.ac

Received: November 3, 2020

Revised: December 21, 2020

Accepted: January 18, 2021

\title{
Influence of Frailty on Life Expectancy in Octogenarians After Lumbar Spine Surgery
}

\author{
Hyun Jun Jang, Dong Kyu Chin, Jeong Yoon Park, Sung Uk Kuh, Keun Su Kim, \\ Yong Eun Cho, Kyung Hyun Kim
}

Department of Neurosurgery, Spine and Spinal Cord Institute, Gangnam Severance Hospital, Yonsei University College of Medicine, Seoul, Korea

Objective: Many studies have reported positive surgical outcomes and decreased mortality after spine surgery in the elderly population, including patients between 85 and 90 years of age. Here, in addition to patient age, we investigated the influence of frailty on short and long-term mortality in octogenarians after lumbar surgery.

Methods: We performed a retrospective analysis of 162 patients over 80 years of age who underwent posterior lumbar fusion or decompressive laminectomy between January 2011 and September 2016. We examined patient survival and modified frailty index $(\mathrm{mFI})$ from medical records.

Results: By October 2019, 29 of 162 patients had expired (follow-up period: 1-105 months). Three-month mortality was $1.9 \%$, and 1 -year mortality was $4.9 \%$. Frailty did not affect long-term survival at 1 year but was associated with 3 -month mortality $(\mathrm{p}=0.024)$.

Conclusion: There was no relationship in long-term survival according to frailty in patients 80 years of age or older, but a difference was identified in short-term mortality. When making a surgical decision for lumbar spine surgery in frail patients over 80 years of age, surgeons should pay attention to the short-term prognosis.

Keywords: Lumbar spine surgery, Octogenarians, Frailty, Mortality, Short-term outcome

\section{INTRODUCTION}

The elderly population continues to increase, thereby increasing the need for medical services that support geriatric patients. ${ }^{1}$ The degenerative disease spinal stenosis causes radiculopathy or claudication by narrowing the spinal canals. The resulting decrease in activity in lumbar spinal stenosis patients leads to an increase in morbidity of elderly patients. There are reports that surgical treatment of spinal stenosis improves patient quality of life and increases survival by reducing walking disorders and enabling outdoor activities. ${ }^{2,3}$ However, the elderly has additional comorbidities, increasing the risk of adverse surgical outcomes. It has been reported that major medical complications and mortality are higher after lumbar spinal surgery in patients 80 years of age or older. ${ }^{4-6}$

Recent reports have indicated that comorbidity is different according to frailty, even within the same age group., ${ }^{7,8}$ Frailty, defined as a state of increased vulnerability to poor resolution of homoeostasis after a stressor event, increases the risk of adverse outcomes. A study of United States national database revealed that the frailty index correlated with both mortality and morbidity for all surgical specialties. ${ }^{9}$ Using the simplified frailty measurement index, the modified frailty index $(\mathrm{mFI})$, many studies confirmed that frail patients had higher complication and mortality rate in spinal surgery. ${ }^{10-14}$ However, no research has investigated short-term or long-term survival in octogenarians compared to the average population and whether it is appropriate to operate a spine surgery on patients with increased frailty. The purpose of our study is to identify long- and shortterm ( 3 months and 1 year after surgery) survival of patients over 80 years of age who received lumbar spine surgery by groups according to frailty and investigate the risk factors such as age, 
sex, type of surgery, past history, body mass index (BMI), bone mineral density (BMD), and intraoperative estimated blood loss (EBL).

\section{MATERIALS AND METHODS}

We performed a retrospective analysis of 162 patients over 80 years of age who underwent posterior lumbar fusion or decompressive laminectomy for lumbar spinal stenosis between January 2011 and September 2016. Exclusion criteria included (1) history of cancer or other malignancy to influence life expectancy, (2) surgery for infectious lesions (infectious spondylitis or abscess), (3) any history of infection within 3 months of surgery, and (4) quadriplegic or paraplegic patients.

We collected data from hospital records for sex, date of birth, type of surgery, past histories, BMI, BMD, EBL of surgery, and date of death. Date of death was verified by records from the National Health Insurance Corporation. The Institutional Review Board of Gangnam Severance Hospital approved this study (2020-0003-001) with a waiver of informed consents

We calculated the mFI of each patient based on a previously published method. ${ }^{9}$ The $\mathrm{mFI}$ was simplified from the Canadian Study of Health and Aging Frailty Index, which is based on the theory of accumulating properties that are strongly associated with overall modality of community-dwelling functions. The mFI consists of 11 components: a history of diabetes mellitus, dependent functional status, chronic obstructive pulmonary disease or pneumonia, congestive heart failure, myocardial infarction, percutaneous coronary intervention, stenting, or angina, hypertension requiring medication, peripheral vascular disease or ischemic rest pain, impaired sensorium, transient ischemic attack or cerebrovascular accident, and cerebrovascular accident with neurological deficits (Table 1). The $\mathrm{mFI}$ was calculated as the modified frailty score (i.e., the number of deficits present) divided by 11, thus providing an index with a range of 0 to 1 . We categorized patients as robust $(\mathrm{mFI}=0)$, prefrail $(\mathrm{mFI}>0$ and $<0.21)$, and frail $(\geq 0.21)$ based on previous data defining frailty as an index greater than $0.21 .^{7}$

Data are described as the mean (standard deviation) or median (interquartile range [IQR]). We calculated the survival curve using the Kaplan-Meier survival method and obtained the survival rate for 8 years. We analyzed variation of the survival curve according to structure using log-rank tests. We used linear-bylinear association tests to determine the relationship between 3 months mortality, 1-year modality, and frailty, and the Fisher exact test to identify relationships between sex, age group, and type of surgery. Cox regression analysis was used to compare the survival rate according to sex, type of surgery, and osteoporosis. Hazard ratios and 95\% confidence intervals (CIs) were calculated for parameters. All statistical analyses were performed using the IBM SPSS Statistics ver. 25.0 (IBM Co., Armonk, NY, USA).

\section{RESULTS}

Of the total 162 patients, mean age was $82.3 \pm 2.7$ years at surgery (range, $80-92$ years). Eighty patients (49.4\%) were male (mean age, 83.06 \pm 3.31 ) and 82 patients (50.6\%) were female (mean age, $81.62 \pm 1.80$ ). The average male age was higher than that of females ( $\mathrm{p}=0.001)$. The age distribution was as follows: 80 to 84 years (136 patients; $84 \%$ ), 85 to 89 years (22 patients; $13.6 \%$ ), and over 90 years (4 patients; $2.5 \%$ ). A total of 85 pa-

Table 1. Eleven variables of the modified frailty index

\begin{tabular}{lc}
\hline Variable & No. (\%) \\
\hline 1. History of diabetes mellitus & $47(29.0)$ \\
2. Functional status 2 (not independent) & $25(15.4)$ \\
3. History of chronic obstructive pulmonary disease or pneumonia & $5(3.1)$ \\
4. History of congestive heart failure & $1(0.6)$ \\
5. History of myocardial infarction & $1(0.6)$ \\
6. History of percutaneous coronary intervention, stenting, or angina & $18(11.1)$ \\
7. History of hypertension requiring medication & $113(69.8)$ \\
8. History of peripheral vascular disease or ischemic rest pain & $4(2.5)$ \\
9. History of impaired sensorium & $5(3.1)$ \\
10. History of transient ischemic attack or cerebrovascular accident & $4(2.5)$ \\
11. History of cerebrovascular accident with neurological deficit & $5(3.1)$
\end{tabular}


tients underwent posterior fusion surgery and 77 patients underwent laminectomy.

The average survival of overall patients was $98.1 \%$ at 3-month postsurgery, $95.1 \%$ at 1 year, $80.9 \%$ at 5 years, and $74 \%$ at 8 -year postsurgery (48-month median follow-up: 1-105 months). No patient was lost to follow-up. Survival according to sex had no statistical significance $(\mathrm{p}=0.051)$. Three patients expired at 3 months and 8 patients at 1 year postoperatively (Table 2, Fig. 1).

The mean age of patients who underwent posterior lumbar fusion $(81.75 \pm 2.19$ years) was lower than in patients who underwent laminectomy $(82.86 \pm 3.09$ years $)(p=0.01)$. Except for age, the BMD, BMI, and $\mathrm{mFI}$ were not significantly different between the laminectomy group and the posterior lumbar fusion group (Table 3). The mean survival time was higher in patients who underwent fusion surgery (95.86 months [89.8-101.92]) compared to laminectomy (79.17 months [71.82-86.52]) $(\mathrm{p}=0.03)$.

To see an effect on the survival according to the fusion level, we divided fusion surgery patients into who underwent 1 - or 2-level fusion $(n=65)$ and those who underwent more than 3-level fusion surgery $(n=12)$. There was no significant difference in age, EBL, operation time. $\mathrm{mFI}$ scores were lower in more than 3-level fusion surgery than 1- or 2-level fusion surgery $(0.15 \pm 0.1$ vs. $0.08 \pm 0.08, p=0.014)$. Both in the log-rank test for overall survival time and in the mortality rate at 3 months and 1 year, there was no statistically significant difference.

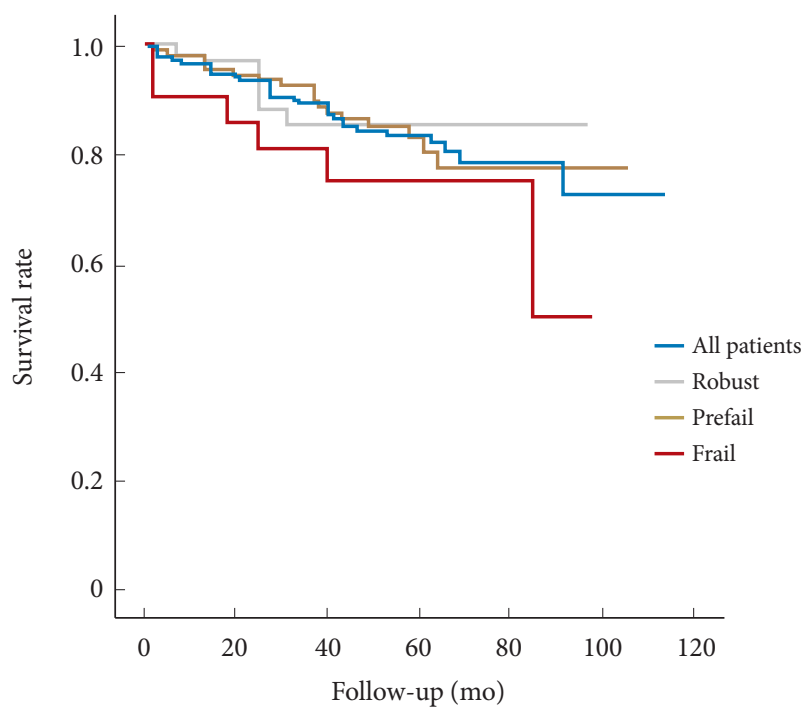

Fig. 1. Kaplan-Meier 8-year survival curves in patients who underwent spine surgery for spinal stenosis according to frailty.

Table 2. Demographic characteristics and cumulative 8-year survival in patients who underwent lumbar spine surgery

\begin{tabular}{|c|c|c|c|c|c|c|c|c|}
\hline Variable & No. $(\%)$ & $\begin{array}{l}\text { Age }(y r) \\
\text { mean } \pm \text { SD }\end{array}$ & $\mathrm{p}$-value & $\begin{array}{c}\text { 3-Month } \\
\text { survival (\%) }\end{array}$ & $\begin{array}{c}\text { 1-Year } \\
\text { survival (\%) }\end{array}$ & $\begin{array}{c}\text { 5-Year } \\
\text { survival (\%) }\end{array}$ & $\begin{array}{c}\text { 8-Year } \\
\text { survival (\%) }\end{array}$ & $\begin{array}{l}\text { Mean survival time } \\
(95 \% \mathrm{CI})\end{array}$ \\
\hline Total & $162(100)$ & $82.33 \pm 2.75$ & & 98.1 & 95.1 & 80.9 & 74 & $88.64(83.15-94.13)$ \\
\hline \multicolumn{9}{|l|}{ Sex } \\
\hline Male & $80(49)$ & $83.06 \pm 3.31$ & & 98.8 & 96.3 & 85 & 60.4 & $82.97(74.96-91.84)$ \\
\hline Female & $82(51)$ & $81.62 \pm 1.80$ & $<0.001^{\star}$ & 97.6 & 93.9 & 90.2 & 85.1 & 88.58 (82.51-94.66) \\
\hline p-value & & & & 0.618 & 0.68 & & & 0.051 \\
\hline \multicolumn{9}{|c|}{ Type of surgery } \\
\hline Fusion & $77(48)$ & $81.75 \pm 2.19$ & & 97.4 & 96.1 & 88.5 & 88.5 & $95.86(89.8-101.92)$ \\
\hline Nonfusion & $85(53)$ & $82.86 \pm 3.09$ & $0.01^{\star}$ & 98.8 & 94.1 & 74.9 & 62.9 & $79.17(71.82-86.52)$ \\
\hline $\mathrm{p}$-value & & & & 0.605 & 1.000 & & & $0.032^{*}$ \\
\hline \multicolumn{9}{|l|}{ Age (yr) } \\
\hline $80-84$ & $136(84)$ & - & & 98.5 & 95.6 & 80.5 & 78.2 & $86.38(81.21-91.56)$ \\
\hline $85-89$ & $22(14)$ & - & & 95.5 & 90.9 & 81.8 & 40.9 & $82.71(67.61-97.81)$ \\
\hline$\geq 90$ & $4(2.5)$ & - & & 100 & 100 & 25 & No data & $39.25(19.56-58.94)$ \\
\hline \multicolumn{9}{|l|}{ Frailty } \\
\hline Robust & $34(21)$ & $82.18 \pm 3.42$ & & 100 & 97.1 & 85.3 & 85.3 & $85.06(76.14-93.98)$ \\
\hline Prefail & $107(66)$ & $82.32 \pm 2.63$ & & 99.1 & 95.3 & 80.8 & 78 & $90.17(83.87-96.47)$ \\
\hline Frail & $21(13)$ & $82.67 \pm 2.13$ & 0.81 & 90.5 & 90.5 & 75.2 & 50.1 & $73.96(58.56-89.36)$ \\
\hline p-value & & & & $0.043^{*}$ & 0.109 & & & 0.381 \\
\hline
\end{tabular}

SD, standard deviation; CI, confidence interval. ${ }^{*} \mathrm{p}<0.05$, statistically significant difference. 
Table 3. Correlates of patients according to surgery type

\begin{tabular}{|c|c|c|c|c|}
\hline Variable & $\begin{array}{l}\text { All patients } \\
(\mathrm{n}=162)\end{array}$ & $\begin{array}{l}\text { Posterior lumbar fusion } \\
\qquad(\mathrm{n}=77)\end{array}$ & $\begin{array}{l}\text { Laminectomy } \\
\qquad(\mathrm{n}=85)\end{array}$ & p-value \\
\hline Age (yr) & $82.33 \pm 2.75$ & $81.75 \pm 2.19$ & $82.9 \pm 3.09$ & $0.01^{\star}$ \\
\hline Sex, male:female & $80: 82$ & $43: 42$ & $37: 40$ & 0.747 \\
\hline Body mass index $\left(\mathrm{kg} / \mathrm{m}^{2}\right)$ & $23.2 \pm 3.5$ & $23.0 \pm 3.42$ & $23.39 \pm 3.59$ & 0.485 \\
\hline BMD (T-score) & $-2.11 \pm 1.04$ & $-2.05 \pm 1.13$ & $-2.18 \pm 0.96$ & 0.464 \\
\hline $\mathrm{EBL}(\mathrm{mL})$ & $454 \pm 398.3$ & $715 \pm 374.4$ & $219 \pm 242.5$ & $<0.001^{\star}$ \\
\hline $\mathrm{mFI}$ & $0.141 \pm 0.108$ & $0.139 \pm 0.100$ & $0.142 \pm 0.115$ & 0.842 \\
\hline Operation time (min) & $152.8 \pm 70.6$ & $200 \pm 66.0$ & $110 \pm 41.6$ & $<0.001^{\star}$ \\
\hline ASA PS classification & $2.44 \pm 0.71$ & $2.53 \pm 0.64$ & $2.36 \pm 0.77$ & 0.136 \\
\hline
\end{tabular}

Values are presented as mean \pm standard deviation or number.

BMD, bone mineral density; EBL, estimated blood loss; mFI, modified frailty index; ASA PS, American Society of Anesthesiologists physical status.

${ }^{*} \mathrm{p}<0.05$, statistically significant difference.

Table 4. Patient demographics according to frailty group and components of the modified frailty index

\begin{tabular}{|c|c|c|c|c|c|}
\hline Variable & All patients $(n=162)$ & Robust $(\mathrm{n}=34)$ & Prefail $(\mathrm{n}=107)$ & Frail $(n=21)$ & p-value \\
\hline Age (yr) & $82.33 \pm 2.75$ & $82.18 \pm 3.42$ & $82.32 \pm 2.63$ & $82.67 \pm 2.13$ & 0.148 \\
\hline Sex, male:female & $80: 82$ & $22: 12$ & $47: 60$ & $11: 10$ & 0.225 \\
\hline Mean body mass index $\left(\mathrm{kg} / \mathrm{m}^{2}\right)$ & 23.2 & 22.8 & 23.4 & 23.1 & 0.916 \\
\hline Mean BMD (T-score) & -2.1 & -2 & -2.2 & -1.8 & 0.399 \\
\hline \multicolumn{6}{|l|}{ Type of surgery } \\
\hline Fusion:laminectomy & $77: 85$ & $17: 17$ & $50: 57$ & $10: 11$ & 0.892 \\
\hline Mean EBL (mL) & 454.8 & 515.3 & 432.2 & 471.9 & 0.744 \\
\hline Mean operation time (min) & 152.8 & 162 & 152.5 & 139.5 & 0.588 \\
\hline Mean ASA PS classification & 2.44 & 2.29 & 2.43 & 2.76 & 0.660 \\
\hline
\end{tabular}

Values are presented as mean \pm standard deviation.

BMD, bone mineral density; EBL, estimated blood loss; ASA PS, American Society of Anesthesiologists physical status.

\section{Survival According to Frailty}

The mean and median $\mathrm{mFI}$ of the study population were 0.18 (standard deviation, 0.09) and 0.09 (IQR, 0.09-0.18), respectively. The maximum mFI was 0.45 (frailty score of 5), which was present in 1 patient. A total of 34 patients (21.0\%) were robust, 107 (66.0\%) were prefrail, and 21 (13.0\%) were frail. The prevalence of individual frailty components is shown in Table 1. Hypertension was the most common individual component of frailty, present in $69.8 \%$ of the population. There was no difference in age, sex, BMI, BMD, surgery type, EBL, operation time, and ASA physical status classification among the groups (Table 4). The 8-year survival of robust, prefrail, and frail patient groups was $85.3 \%, 78 \%$, and $50.1 \%$, respectively, and no difference between each survival curve was identified. However, with linearby-linear association tests, 3-month survival was related to frailty at $100 \%$ in robust, $99.1 \%$ in prefrail, and $90.5 \%$ in frail patients
Table 5. Cox analysis of factors related to patient survival

\begin{tabular}{lccc}
\hline Risk factor & $\begin{array}{c}\text { Hazard } \\
\text { ratio }\end{array}$ & 95\% CI & p-value \\
\hline Modified frailty index 0.09 vs. 0 & 1.232 & $0.45-3.40$ & 0.69 \\
Modified frailty index >0.18 vs. 0 & 1.972 & $0.56-6.93$ & 0.29 \\
Age & 1.125 & $1.00-1.26$ & $0.04^{*}$ \\
Fusion to laminectomy & 0.442 & $0.19-1.02$ & 0.06 \\
Body mass index & 1.000 & $0.90-1.11$ & 0.99 \\
Bone mineral density & 1.454 & $0.99-2.13$ & 0.05 \\
Male to female & 1.563 & $0.67-3.62$ & 0.30 \\
\hline
\end{tabular}

CI, confidence interval.

${ }^{*} \mathrm{p}<0.05$, statistically significant difference.

$(\mathrm{p}=0.043)($ Table 2, Fig 1).

In Cox multivariate analysis, age (hazard ratio [95\% CI], 1.125 [1.003-1.262]) was a variable associated with survival. Howev- 
Table 6. Characteristics of mortality cases within 1 year after surgery

\begin{tabular}{|c|c|c|c|c|c|c|c|}
\hline Case No. & Age/sex & Underlying Diseases & $\begin{array}{l}\text { mFI } \\
\text { score }\end{array}$ & Frailty & Surgery type & Cause of death & $\begin{array}{l}\text { Mortality day } \\
\text { after surgery }\end{array}$ \\
\hline 1 & 80/Female & Hypertension & 0.09 & Prefrail & 1-Level PLIF+PS & Sudden cardiac arrest & 5 Days \\
\hline 2 & 80/Female & $\begin{array}{l}\text { Hypertension, asthma, } \\
\text { cor pulmonale }\end{array}$ & 0.27 & Frail & 1-Level laminectomy & Pneumonia & 35 Days \\
\hline 3 & 81/Male & $\begin{array}{l}\text { Hypertension, impaired ADL, } \\
\text { delirium }\end{array}$ & 0.27 & Frail & 3-Level PLF+PS & Pneumonia & 43 Days \\
\hline 4 & 86/Female & Hypertension & 0.09 & Prefrail & 1-Level laminectomy & Pancreatic cancer & 4 Months \\
\hline 5 & 82/Male & None & 0.00 & Robust & 3-Level laminectomy & Traffic accident & 6 Months \\
\hline 6 & 80/Male & Hypertension & 0.09 & Prefrail & 1-Level PLIF+PS & Sudden cardiac arrest & 10 Months \\
\hline 7 & 83/Female & Hypertension, diabetes mellitus & 0.18 & Prefrail & 1-Level laminectomy & Stroke & 11 Months \\
\hline 8 & 83/Female & Hypertension, impaired ADL & 0.18 & Prefrail & 1-Level laminectomy & Sudden cardiac arrest & 11 Months \\
\hline
\end{tabular}

mFI, modified frailty index; ADL, activities of daily living; PLIF, posterior lumbar interbody fusion; PLF, posterolateral fusion; PS, pedicle screws fixation.

er, frailty, type of surgery, BMD, BMI, EBL, surgery time, fusion level, and sex did not affect patient survival (Table 5).

Table 6 shows the details of patients who expired within 1 year after surgery. Two frail patients expired of pneumonia within 3 months after surgery and one prefrail patient expired of sudden cardiac arrest 5 days after surgery. One robust patient expired due to a traffic accident 6 months after surgery, and the other 4 were prefrail patients who expired within a year due to medical problems. Patients who expired within 3 months after surgery are described in detail below.

\section{Early Mortality Cases}

1) Case 1

An 80-year-old prefrail female patient with a history of hypertension, lumbar discectomy, underwent revision laminectomy with 900-mL EBL, and operation time of 160 minutes. On the 5th day after surgery, he expired due to sudden cardiac arrest in the ward.

\section{2) Case 2}

An 80-year-old frail female patient with hypertension, asth$\mathrm{ma}$, and cor pulmonale underwent revision posterior lumbar interbody fusion surgery on the site where partial hemilaminectomy was performed 12 years ago, and the operation time was slightly longer with 245 minutes, EBL was $700 \mathrm{~mL}$, and incidental durotomy was occurred during the operation. After surgery, she got an acute renal failure and a pneumonia, and on the 35th day after surgery, the patient expired due to multiorgan failure following a pneumonia deterioration.

\section{3) Case 3}

An 81-year-old frail male patient with hypertension, dementia, and impaired activities of daily living was presented with quadriparesis after a trauma to the site of stenosis. Before a surgery, a pneumonia was suspected on his chest $\mathrm{x}$-ray, 3-level posterolateral fusion and pedicle screw fixation emergency surgery were performed with $350 \mathrm{~mL}$ of EBL and 195 minutes of surgery time. He expired on day 43 due to pneumonia deterioration.

\section{DISCUSSION}

People older than 80 years now constitute a rapidly growing portion of the population, and the need for lumbar spinal surgery for elderly patients is increasing. ${ }^{15}$ We have seen short- and long-term survival in lumbar spinal surgery in patients over 80 years according to frailty.

It has already been revealed that in the case of 1- or 2-level lumbar fusion surgery, age over 80 years is an important factor in 3-month mortality rate and 1-year mortality rate, which is 3.5-fold and 2.6-fold higher than those of patients aged between 65 and 79, respectively. ${ }^{4}$ However, in 10-year survival, it was reported that standardized mortality ratio in patients who received lumbar spinal surgery in the 70- to 85-year age group was 0.45 compared to the general population group. ${ }^{16}$ There are debates as to whether surgery has a positive or negative influence on long-term survival, but there is no doubt that surgical treatment has a better outcome for intractable pain or radiculopathy. ${ }^{17,18}$ This is because of reducing coronary artery disease by improving ambulation, increasing mobility, and increasing cardiovas- 
cular fitness by reducing intractable pain..$^{19,20}$

Fusion surgery has higher rates of postoperative complication in older age groups than decompression surgery, but little is known about the long-term survival after surgery. Posterior lumbar fusion surgery is known to have more complications than decompression surgery due to increased blood loss, longer operation time, and higher infection rate. ${ }^{21,22}$ In this study, unexpectedly, patients with fusion surgeries showed higher mean survival compared to patients with laminectomy. We can presume that there would be selection bias because surgeons prefer posterior lumbar fusion for patients who are healthier preoperatively. Kim et al. ${ }^{16}$ discussed that in patients over 65 years of age, 10-year survival rate of patients with fusion surgery was greater than the adjusted corresponding portion in general due to these reasons. Thus, we investigated the differences between laminectomy and posterior lumbar fusion groups with regard to age, BMI, BMD, and mFI. Given our results that only age was different between the groups, we presumed that it might be influenced by the higher average age of the decompression surgery group than the fusion surgery group, but there could be many other significant differences that were not evaluated in this study.

Previous reports have shown that higher frailty resulted in increased postsurgical complication rates and higher mortality. ${ }^{10,23}$ In these studies, $2.3 \%$ to $10 \% 3$-month mortality rates have been reported after spinal surgery in frail patient groups. ${ }^{24-26} \mathrm{In}$ our study, unlike these studies, survivals were compared using frailty indexes with a group of patients over 80 years of age who underwent posterior lumbar surgery for a single disease. Our result was a 3-month mortality of $9.5 \%$ in the frail patient group, both deaths of which were due to septic shock caused by pneumonia after surgery. On the other hand, robust patients within 1 year after surgery showed no death due to medical problems other than a traffic accident. Although our study did not reveal the relationship between longer operation time, longer fusion level, larger EBL, and early mortality, however, when reviewing our early mortality cases, careful attention should be paid to the surgical decision of patients with an unexpected long surgery time and cardiopulmonary problems under general anesthesia in patients over 80 years of age. In addition, when fusion surgery patients were grouped into 1- or 2-level fusion and 3- or more level fusions, only 12 patients with fusion surgery at level 3 or higher were included. It could be a type II error that there was no difference in a short-term mortality and overall survival time in long-level fusion surgery where there are more EBL and longer operation time. A large group study is necessary to re- veal this.

Large-scale studies continue to show that high frailty index is a risk factor related to patient long-term survival. ${ }^{7,27-29}$ As age increases, frailty index tends to increase, which is associated with the accumulation of adverse events below the subcellular level, indicating that the risk of adverse events may differ even in people of the same chorological age. ${ }^{30}$ In the Cox multivariate analysis of our study, we compared survival for 8 years according to frailty, and no statistical significance was found. The maximal mFI of enrolled patients was 0.45 , which was present in only 1 patient. Since patients with poor health conditions, as with cancer history excepted from this study, are likely to be excluded before surgery due to surgeon selection bias, the frailty of octogenarians in the general population and the patient group in our study could be different and a bit healthier preoperatively. This exclusion of severe frail patients may have concluded that the survival was associated only with age and not with frailty in multivariate analysis. However, the 3-month mortality rate was significantly higher in patients with an $\mathrm{mFI}$ over 0.21 according to our results. We thought that mFIs have a clinical impact on perioperative period. For long-term follow-up, there would be various confounding factors influencing life expectancy. And, this selection bias, one on the main limitation of this study could be teased out by using a propensity score matching.

The major strengths of this study were that we determined the survival rates of patients with long follow-up without a follow-up loss and surveyed patients with obtaining an accurate survival rate and causes of death. Limitations of this study include the lack of a control group, small patient groups, and its retrospective nature. To overcome this limitation, our survival should be compared with an age and sex-matched studies. The number of patients over the age of 90 and frail group was small, so there was a limit to obtaining more powerful statistical results. Surgeon selection bias to rule out unhealthy patients from surgery was inevitable in this study. A randomized controlled trial with larger patient groups would be better to control for this bias.

\section{CONCLUSION}

Posterior lumbar surgery in patients over 80 years of age with frailty showed higher mortality in the short-term period, but no difference was found in long-term survival. Therefore, caution is needed regarding short-term postoperative complications when frail patients undergo such a surgery. 


\section{CONFLICT OF INTEREST}

The authors have nothing to disclose.

\section{REFERENCES}

1. 2018 Population and Housing Census [Internet]. Daejeon (Korea): Statistics Korea; 2019 [cited 2019 Aug 29]. Available from: http://kostat.go.kr/portal/eng/pressReleases/1/index.board? bmode $=$ read $\& b S e q=\& a S e q=378504 \&$ pageNo $=1$ \&rowNum $=10 \&$ navCount $=10 \&$ currPg $=\&$ searchInfo $=$ srch \&sTarget=title\&sTxt=population.

2. Jansson KA, Németh G, Granath F, et al. Health-related quality of life (EQ-5D) before and one year after surgery for lumbar spinal stenosis. J Bone Joint Surg Br 2009;91:210-6.

3. Tosteson AN, Tosteson TD, Lurie JD, et al. Comparative effectiveness evidence from the spine patient outcomes research trial: surgical vs. non-operative care for spinal stenosis, degenerative spondylolisthesis and intervertebral disc herniation. Spine 2011;36:2061.

4. Puvanesarajah V, Jain A, Shimer AL, et al. Complications and mortality following 1 to 2 level lumbar fusion surgery in patients above 80 years of age. Spine 2017;42:437-41.

5. Umekawa M, Takai K, Taniguchi M. Complications of spine surgery in elderly Japanese patients: implications for future of world population aging. Neurospine 2019;16:780-8.

6. Chung SK, Kim KT, Kim YB. Surgical complications of transforaminal lumbar interbody fusion in elderly patients. Korean J Spine 2010;7:167-72.

7. Rockwood K, Song X, Mitnitski A. Changes in relative fitness and frailty across the adult lifespan: evidence from the Canadian National Population Health Survey. CMAJ 2011; 183:E487-94

8. Leven DM, Lee NJ, Kim JS, et al. Frailty is predictive of adverse postoperative events in patients undergoing lumbar fusion. Global Spine J 2017;7:529-35.

9. Velanovich V, Antoine H, Swartz A, et al. Accumulating deficits model of frailty and postoperative mortality and morbidity: its application to a national database. J Surg Res 2013;183:104-10.

10. Flexman AM, Charest-Morin R, Stobart L, et al. Frailty and postoperative outcomes in patients undergoing surgery for degenerative spine disease. Spine J 2016;16:1315-23.

11. Leven DM, Lee NJ, Kothari P, et al. Frailty index is a significant predictor of complications and mortality after surgery for adult spinal deformity. Spine 2016;41:E1394-401.
12. Simcox T, Antoku D, Jain N, et al. Frailty syndrome and the use of frailty indices as a preoperative risk stratification tool in spine surgery: a review. Asian Spine J 2019;13:861.

13. Phan K, Kim JS, Lee NJ, et al. Frailty is associated with morbidity in adults undergoing elective anterior lumbar interbody fusion (ALIF) surgery. Spine J 2017;17:538-44.

14. Charest-Morin R, Street J, Zhang H, et al. Frailty and sarcopenia do not predict adverse events in an elderly population undergoing non-complex primary elective surgery for degenerative conditions of the lumbar spine. Spine J 2018;18: 245-54.

15. Lee $\mathrm{CH}$, Chung $\mathrm{CK}$, Kim $\mathrm{CH}$, et al. Health care burden of spinal diseases in the Republic of Korea: analysis of a Nationwide Database from 2012 through 2016. Neurospine 2018;15:66-76.

16. Kim HJ, Lee HM, Kim HS, et al. Life expectancy after lumbar spine surgery: one-to eleven-year follow-up of 1015 patients. Spine 2008;33:2116-21.

17. Amundsen T, Weber H, Nordal HJ, et al. Lumbar spinal stenosis: conservative or surgical management? A prospective 10-year study. Spine 2000;25:1424-36.

18. Atlas SJ, Keller RB, Wu YA, et al. Long-term outcomes of surgical and nonsurgical management of lumbar spinal stenosis: 8 to 10 year results from the maine lumbar spine study. Spine 2005;30:936-43.

19. Berlin JA, Colditz GA. A meta-analysis of physical activity in the prevention of coronary heart disease. Am J Epidemiol 1990;132:612-28.

20. Fletcher GF, Balady G, Blair SN, et al. Statement on exercise: benefits and recommendations for physical activity programs for all Americans: a statement for health professionals by the Committee on Exercise and Cardiac Rehabilitation of the Council on Clinical Cardiology, American Heart Association. Circulation 1996;94:857-62.

21. Fritzell P, Hägg O, Nordwall A, et al. Complications in lumbar fusion surgery for chronic low back pain: comparison of three surgical techniques used in a prospective randomized study. A report from the Swedish Lumbar Spine Study Group. Eur Spine J 2003;12:178-89.

22. Glassman SD, Alegre G, Carreon L, et al. Perioperative complications of lumbar instrumentation and fusion in patients with diabetes mellitus. Spine J 2003;3:496-501.

23. Ali R, Schwalb JM, Nerenz DR, et al. Use of the modified frailty index to predict 30-day morbidity and mortality from spine surgery. J Neurosurg Spine 2016;25:537-41.

24. Ondeck NT, Bohl DD, Bovonratwet P, et al. Discriminative 
ability of commonly used indices to predict adverse outcomes after poster lumbar fusion: a comparison of demographics, ASA, the modified Charlson Comorbidity Index, and the modified Frailty Index. Spine J 2018;18:44-52.

25. Reid DBC, Daniels AH, Ailon T, et al. Frailty and health-related quality of life improvement following adult spinal deformity surgery. World Neurosurg 2018;112:e548-54.

26. Yagi M, Fujita N, Okada E, et al. Impact of frailty and comorbidities on surgical outcomes and complications in adult spinal disorders. Spine 2018;43:1259-67.

27. Fried LP, Tangen CM, Walston J, et al. Frailty in older adults: evidence for a phenotype. J Gerontol A Biol Sci Med Sci 2001; 56:M146-56.

28. Bandeen-Roche K, Xue QL, Ferrucci L, et al. Phenotype of frailty: characterization in the women's health and aging studies. J Gerontol A Biol Sci Med Sci 2006;61:262-6.

29. Ensrud KE, Ewing SK, Taylor BC, et al. Comparison of 2 frailty indexes for prediction of falls, disability, fractures, and death in older women. Arch Intern Med 2008;168:382-9.

30. Kirkwood TBL. Understanding the odd science of aging. Cell 2005;120:437-47. 